\title{
Myxomycete plasmodial biology: a review
}

\author{
Clark $\mathbf{J}^{1}$ and Haskins $\mathbf{E F}^{2}$ \\ ${ }^{1}$ Department of Biology, University of Kentucky, Lexington, Kentucky 40506 \\ ${ }^{2}$ Department of Biology, University of Washington, Seattle, Washington 98195
}

Clark J, Haskins EF 2015 - Myxomycete plasmodial biology: a review. Mycosphere 6(5), 643-658, Doi 10.5943/Mycosphere/6/6/1

\begin{abstract}
The most characteristic stage of a myxomycete is the assimilative plasmodium, a naked free-living multinucleate motile mass of protoplasm which varies in size and morphological details with species. The plasmodium is formed from the amoeboflagellate stage by either of two methods which can be found within a particular species: by fusion of two haploid cells carrying different mating types to form a zygote, or by conversion of an apogamic diploid cell directly into a plasmodium. The plasmodium, which is generally covered by a slime sheath, is multinucleate and wall-less, and is therefore capable of movement which occurs by means of differential protoplasmic streaming. The larger plasmodial types (aphanoplasmodia and phaneroplasmodia) routinely form a reticulate structure where different regions of the plasmodia undergo a continuous cycle of separation and coalescence; therefore they also have a complex genetic system that prevents the fusion of genetically unrelated plasmodia. These plasmodia engulf bacteria, yeast and other organic matter, which they surround and digest in food vacuoles. Under adverse conditions (cold, drying) the plasmodium can form a resistant sclerotium which can revive and continue growth when conditions improve. However, the end point purpose of the plasmodium is sporulation with the production of spores and their germination to produce the alternate amoeboflagellate stage; which is generally triggered by the mature plasmodium undergoing starvation in the presence of light.
\end{abstract}

Key words - aphanoplasmodium - coalescence - phaneroplasmodium - protoplasmodium, sclerotium - senescence - sporulation - syngamy

\section{Introduction}

The two assimilative stages of the myxomycetes are the plasmodium and the amoeboflagellate; with the plasmodium being the larger multinucleate more conspicuous stage which, during sporulation, produces many small spores that germinate into the small uninucleate amoeboflagellates. The plasmodium is a wall-less (generally slime covered) free-living multinucleate, motile mass of protoplasm which varies in size and morphological detail with age and species. These plasmodia, some of which are occasionally seen in the field, vary from large (several centimeters across) colorful gelatinous masses to minute colorless blobs. They feed on bacteria, fungi, and any other organic matter that is encountered which they can engulf. Plasmodia usually inhabit environments, such as soil, dead wood, and various plant litter and debris, which are moist and support bacteria and other decay microorganisms (Stephenson \& Landolt 1996). Some 
species, such as Physarum polycephalum, seem to prefer to grow on or just under the surface of the substrate; however, the great majority of species probably spend most or all of their active life within the substrate. Under the influence of desiccation, low temperature and other unfavorable conditions, the plasmodium can be converted into a resting stage sclerotium, which reverts to an active plasmodium when conditions again become favorable.

\section{Plasmodial Formation}

Plasmodial formation concerns the mechanisms that produce the plasmodium and the limitations imposed on these mechanisms by the environment.

\section{Mechanisms}

Plasmodia are produced by the amoeboflagellate stage either by the formation of a diploid zygotic cell by means of sexual fusion, or by the conversion of an apogamic diploid amoeboflagellate into a plasmodium (see reviews by Clark \& Haskins 2010, 2013). In the sexual cycle amoeboflagellates differing at a multiple allelic mating system (Collins 1963) undergo syngamy (Bailey et al. 1990) after they have become competent upon reaching a critical cell density (Shipley \& Holt 1982); while in the apogamic cycle, the amoeboflagellates are diploid, due to automixis (see Clark \& Haskins 2013), and convert to plasmodia when they become competent. This zygotic or diploid amoeboflagellate cell apparently then undergo a number of biochemical changes in its cell membrane (Ross \& Shipley 1973) and a series of mitotic nuclear divisions without cell division to produce the multinucleate plasmodium.

\section{Environment}

While any condition that prevents amoeboflagellates from achieving competence will prevent plasmodial development, the requirements for plasmodia formation are apparently more stringent than for growth, since plasmodia will often not be produced by vigorously growing amoeboflagellates (Gray \& Alexopoulos 1968). The temperature limits for plasmodial formation have been determined for a number of species: 7-30 ${ }^{\circ} \mathrm{C}$ for Fuligo septica (Constantineanu (1907), $14-30^{\circ}$ for Physarum didermoides (Constantineanu (1907), 5-30 ${ }^{\circ} \mathrm{C}$ for Didymium squamulosum

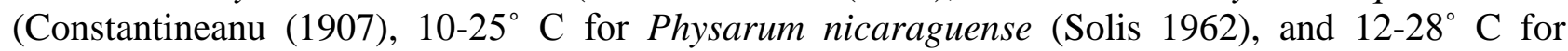
Didymium iridis (Clark unpublished). Recent research on the nivicolous (snow bank) species Lepidoderma chailletii and Physarum nivale indicate that plasmodia can only form at temperatures of $0-2^{\circ} \mathrm{C}$ in the presence of a water film (Shchepin et al. 2014). The presence of free water also appears to be required for plasmodial formation in some species of the Stemonitales (Alexopoulos 1960, Wollman \& Alexopoulos 1964), although it is apparently an enhancer in other species that are capable of plasmodial formation on a moist substrate such as agar (Indira \& Kalyanasundaram (1963). The $\mathrm{pH}$ of the substrate is apparently a key factor that affects plasmodial formation, which has been examined in some detail in a few species. Collins and Tang (1973) found that Physarum polycephalum had an optimum $\mathrm{pH}$ 5-6 range for plasmodial formation, and Shinnick et al. (1978) discovered a gene that affected this $\mathrm{pH}$ range with two alleles producing upper limits of 5.6 and 6 . A pH optimum of 6.2 for plasmodial formation in Didymium iridis (as D. nigripes) (Kerr 1961) and 5.5 for Licea alexopouli (Mock \& Kowalski 1976) has also been reported. While some progress has been made concerning environmental factors which affect plasmodial formation, it is obvious that, to date, we lack a comprehensive understanding of this important process. However, an examination of well documented field studies which record substrates, seasonality, and extremes (snow banks, deserts, etc.), could offer valuable clues for directed culture studies on environmental factors affecting plasmodial formation.

\section{Plasmodial Types}

Considerable variations in plasmodial morphology were recognized by deBary (1887) in his early studies of myxomycete life cycles; however, most early plasmodial investigators (Cienkowski 1863, Strasburger 1884, Howard 1931) generally confined their studies to the rather large easily 
grown reticulated pigmented plasmodia in the Physarales. However, there were reports of nonconforming plasmodia by various authors: a transparent reticulate plasmodium in a number of Stemonitis species (Čelakovský 1893, Miller 1898), and a small amoeboid plasmodium in Licea parasitica (Zukal 1893). While both Watanabe (1932) and Nauss (1947) had expressed the view that not all plasmodia were alike, the description of distinct plasmodial types did not occur until Alexopoulos' 1960 publication where he defined the protoplasmodial, aphanoplasmodial and the phaneroplasmodial types.

\section{Protoplasmodia}

The protoplasmodium is characteristic of the Echinosteliales and possible of the Liceaceae, although the plasmodia found in a number of Licea species appear to be greatly reduced phaneroplasmodia. The uninucleate initial plasmodial cell undergoes nuclear division to form the characteristic mature protoplasmodium, which is a microscopic (20-200 micron diameter) multinucleate colorless amoeboid cell with many short pseudopodia on its periphery and a heavy slime sheath (Alexopoulos 1960, Haskins \& Hinchee 1974). It migrates very slowly over the substrate exhibiting slow irregular cytoplasmic streaming, and does not produce an advancing fanshaped region, although it can display an anterior/posterior orientation. Unlike the other two plasmodial types it does not produce a reticulated plasmodium or fuse with either itself or any other plasmodium (Haskins 1978). Upon reaching an upper size limit the protoplasmodium undergoes binary plasmotomy to produce two daughter plasmodia (Haskins 1978), and upon sporulation, each protoplasmodium produces a single sporangium: Echinostelium minutum (Peterson 1952, Alexopoulos 1960, Haskins 1971), Clastoderma debaryanum (McManus 1961b), Barbeyella minutissima (Jarocki 1939, Schnittler et al. 2000). These plasmodia may represent the ancestral form for all of the myxomycetes, and appear to be evolved for residence in ephemeral habitats on the surfaces of plants and plant debris.

\section{Aphanoplasmodia}

The aphanoplasmodium is characteristic of the Stemonitales and Ceratiomyxales, although DNA evidence indicates that it is unlikely that the plasmodia of the two orders are closely related (Fiore-Donno et al. 2009). The uninucleate initial plasmodial cell usually forms a short multinucleate strand that soon starts to branch and form a reticulum that grows into characteristic mature aphanoplasmodium (Alexopoulos 1960, Haskins 1974); which is a large multinucleate colorless reticulated structure consisting of numerous flattened tubular strands of various sizes (5 to 35 microns in diameter) which lack a slime sheath (Haskins \& Hinchee 1974) and form a complex of large and small meshes with many free ends. The young aphanoplasmodium grows out slowly over the substrate and displays an irregular rapid to slow rhythmic reversible flow inside the strands which have a very thin ectoplasm. Since aphanoplasmodia must fuse with themselves to form the reticulum, they are also capable of coalescence with other genetically identical plasmodia (Haskins 1990). The aphanoplasmodium of Stemonitis flavogenita can reach a diameter of 15 centimeter or more, while Comatricha laxa rarely exceeds 20 millimeters; although they do not seem to have an obvious upper size limit like the protoplasmodium, their sizes appears to be controlled by a mix of genetic and environmental factors and accidental fragmentation of the larger units. The Stemonitis aphanoplasmodia produce a whitish to yellowish pigmented heaped coralloid stage, which produces a heavy slime sheath prior to sporulation, which is highly mobile and usually produces a clump of sporangia (Haskins 1974, 1981). On the other hand the Comatricha plasmodia generally produce one to several individual sporangia from whitish mobile pre-sporangial masses. However, the aphanoplasmodium of Ceratiomyxa fructiculosa which is very similar to Stemonitis flavogenita in morphology, development and size, forms whitish masses of protoplasm that do not undergo extensive migration prior to sporophore formation (Clark et al. 2004, Clark unpublished). The thin reticulate strands and growth in free water; indicate that this plasmodial type probably originated as an adaptation to growth within the cells and connecting pits of dead wet woody materials, where 
the slime sheath would not be needed until it migrated to drier conditions outside the wood where it could sporulate and disperse its spores.

\section{Phaneroplasmodium}

The phaneroplasmodium is characteristic of the Physarales, Trichiales, and most if not all of the Liceales. Phaneroplasmodia are the most common and the most variable of the plasmodial types; not only varying in size from the tiny protoplasmodium-like plasmodia found in the Liceaceae up to the large (30 centimeters) plasmodium of Fuligo septica, but also including the Trichiales plasmodia, which are considered to be a separate type intermediate with the aphanoplasmodia by some (Indira \& Kalyanasundaram 1963, McManus 1962, Ross 1967). The plasmodia of Licea species are small, sluggish lumpy amoeboid masses that typical produce a single sporocarp, and are therefore classified as protoplasmodial by many researchers; however, the plasmodia are usually pigmented and in some species such as Licea biforis, the can be larger branching structures (resembling the early stage of a typical phaneroplasmodium) and produce more than one sporocarp (McManus 1964, Wollman \& Alexopoulos 1967, Clark et al. 2004). Thus, it seems likely that these small plasmodia are examples of ancestral or reduced (due to living in an ephemeral habitat) phaneroplasmodia. The phaneroplasmodia of the Physarales are typified by the well known plasmodia of Physarum polycephalum and Didymium iridis. These plasmodia develop from the small uninucleate initial cell by nuclear division into a small protoplasmodial-like structure, before they form an elongate strand which displays a rhythmic reversal streaming, which soon develops a reticulated fan like region (Alexopoulos 1960). The mature phaneroplasmodium has an anterior fan-shaped sheet of pigmented granular protoplasm, within which channels of streaming protoplasm originate. These channels are orientated from front to back, with shorter connecting channels at right angles and or diagonally to the main channels, with the anterior channels merging into the plasmodium's posterior reticulum of relatively thick strands (Alexopoulos 1960). They also have a noticeable ectoplasm exterior to the streaming center. The phaneroplasmodium observed in the Trichiales is usually a less robust form with a thinner less pigmentation protoplasm than those found in the Physarales. In general it appears that the phaneroplasmodium is adapted to growth in a drier, somewhat exposed habitat, such as on and in the surfaces and structures of plant debris.

\section{Plasmodial Structure}

While plasmodial structure has been intensely studied in the phaneroplasmodia of a number of Physarales species, information of other types and species of myxomycetes, except Echinostelium minutum, is somewhat limited and sporadic; therefore much of this discussion is derived from the Physarum and Echinostelium studies.

\section{Slime Sheath}

The plasmodium of the myxomycetes lack any form of a cell wall, and are thus their only protection from injury or desiccation is the slime sheath present in the protoplasmodial and phaneroplasmodial forms; however, the aphanoplasmodium also produces a slime sheath when it is briefly exposed during sporulation (Haskins 1981). The sheath is a relatively thin, flexible coating outside of the cell membrane which is produced by the growing and moving plasmodium and is left behind as a collapsed tube (slime track) as the plasmodium migrates over the surface of the substrate. Electron microscopic studies (Rhea 1966, Haskins \& Hinchee 1974) of the slime sheath indicate that it is composed of filaments that appear to be attached to the plasma membrane, which could allow it to serve as a sort of flexible exoskeleton. Reports on the biochemical nature of this slime has been inconsistent; with Simon \& Henney (1970) reporting a glycoprotein whose carbohydrate was galactose, and McCormick et al. (1970) characterizing the slime as a polysaccharide consisting of galactose, sulfate, and traces of rhamnose.

\section{Protoplasm}

The plasmodium has the cell organelles found in the normal eukaryotic cell: plasma 
membrane, nuclei, mitochondria, food vacuoles, contractile vacuoles, endoplasmic reticulum, ribosomes, and golgi; as well as pigment granules in the pigmented types. These organelles are typical in their structure and function except for their very small size. The mitochondria have the typical protozoan tubular cristae (Dugas \& Bath 1962) and are quite small (0.5 micron) and are thus difficult to identify with a light microscope. Since the plasmodium feeds by engulfing bacteria and other organic material and organisms, small food vacuoles with partially digested bacteria and other debris are common in the active plasmodium.

\section{Pigment Granules, Pigments and Lipids}

The pigment granules in the phaneroplasmodia are non-standard protoplasmic structures, which account for the range of colors (white, yellows, and reds ranging to near black) found in these plasmodia. These granules are amorphous spheroids surrounded by a membrane (Lieth \& Meyer 1957) and apparently the pigments are localized in these granular structures. The chemical nature of these pigments is not well known, although tetrameric acid derivates (Casser et al. 1987) and carotenoids (Czeczuga 1980) have been reported. While plasmodial color has been reported to be changed by substrate pH (Seifriz \& Zetzmann 1935) and ingested bacteria (Kambly 1939), it is, in general, a constant characteristic, although stable color variants within a species do occur which can affect the color of the sporophore (especially stalk color). Alexopoulos (1964) described a white plasmodial form of Physarella oblonga which produced a lighter colored stalk than the normal yellow plasmodial form; Anderson (1977) isolated a white mutant of the normally yellow plasmodium of Physarum polycephalum, and Collins and Clark (1966) found that a genetically determined cream colored plasmodium in Didymium iridis produced lighter colored stalks than the brown pigmented plasmodium.

The plasmodium also contain high levels of lipids, and recent studies indicate that they could be a possible source for the production of biodiesel fuels, since Physarum polycephalum can be grown on a low-cost carbon source and the lipids can be easily extracted due to the lack of a cell wall (Tran et al. 2015).

\section{Nuclei and Nuclear Division}

The multinucleate condition is the unique and defining feature of a plasmodium. The nuclei in the myxomycete plasmodia, while very small (less than 6 microns in diameter), have a standard eukaryotic structure with a double nuclear membrane, nucleolus, and chromosomes (Aldrich 1966). While early workers considered plasmodial nuclear division to be amitotic (Lister 1893) and sporadic (Schûnemann 1930), later researchers reported synchronous divisions in Physarum polycephalum (Howard 1932, Koevenig \& Jackson 1966), Didymium iridis (Kerr 1976), and Echinostelium minutum (Hinchee \& Haskins 1980), which were entirely intranuclear and lacked centrioles and asters. When Guttes et al. (1959) reported that Physarum polycephalum retained its precise periodic synchronous mitotic division when grown on defined media; a large number of biochemical studies on DNA and RNA synthesis during the different division stages became possible. Readers interested in these biochemical studies should consult Aldrich \& Daniel (1982) for an entry into this area of research.

\section{Physiology}

\section{Protoplasmic Streaming and Locomotion}

Protoplasmic streaming is a universal aspect of myxomycete plasmodial activity, which varies from the sluggish somewhat random movements in the protoplasmodia to an irregular slow shuttle streaming in the aphanoplasmodia to the very rapid shuttle streaming in the channels or veins of the phaneroplasmodia. This streaming serves two purposes: it is a mechanism to move and homogenize the materials and nutritional substances throughout the plasmodium, and is the basic of plasmodial locomotion. This shuttle streaming can be extremely rapid (1,350 microns/second) and moves large amounts of material (Kamiya 1950b), and while streaming may occur in a stationary 
plasmodium, it is required for locomotion. Time-lapse sequences of moving phaneroplasmodia and aphanoplasmodia (Haskins \& Kerr 1976) show a rhythmic pulsation associated with locomotion, which is apparently connected to the shuttle streaming. This streaming generally has a longer duration in the direction of movement causing a bulging out of the anterior fan, followed by a shorter reverse flow (Vouk 1910), giving a two step forward, and one step black movement seen in the pulsations. However, the duration of streaming in one direction is only an indication of bulk flow, since Kamiya (1950a) found that in some cases a short duration flow in the forward direction could still move larger amounts of protoplasm. The flow in any one direction displays a considerable variation and range from one half to 30 minutes (Steward \& Steward 1959) in duration. The apparent motive force for protoplasmic streaming is an ATP fueled (Kamiya et al. 1957) actin-myosin contractile system of fibers (Loewy 1950, Hatano \& Oosawa 1964), which can be visualized in the region where contraction takes place (Nagai \& Kamiya 1966). This localized contraction apparently produces a localized hydraulic pressure that drives the protoplasmic streaming. Kamiya \& Takata (1967) found that the ectoplasm to endoplasm ratio, in different regions of the plasmodium, tended to be balanced by protoplasmic streaming and suggested that this ratio might control the state of actin-myosin fiber activity.

\section{Nutrition}

Myxomycete plasmodia are vegetative stages which undergo growth and differentiate; thus they require energy and organic substrates in order to function. The plasmodium seeks out and takes up organic materials from its environment by means of locomotion and engulfment. When the plasmodial membrane meets a food particle it ceases to advance in that portion and the adjacent regions continue to move and form a pocket around the particle that is eventually closed off to form a food vacuole (Camp 1937b). After the nutrients have been extracted, the food vacuole is egested by a reverse process of the ingestion. While any suitable sized organic material seems to be ingested, the major source of plasmodial nutrition appears to be bacteria. While over 74 species of myxomycetes have been cultivated from spore to spore on agar culture (see Collins 1979), almost all of the species have been grown with a live bacteria or yeast food organisms. Although most of these species could be grown in monoxenic culture (a single live food organism), only a few of the species have been cultured axenically (without a live food organism). Generally the plasmodia are grown on water agar with sterilized oat flakes and a microorganism; isolated from the original culture or a common bacterium addition such as Echerichia coli as a food source (Haskins $\&$ Wrigley de Basanta 2008). The recent finding that plasmodia of some nivicolous species grow only at $0-2^{\circ} \mathrm{C}$ may, in part, be due to a preference for cold adapted microorganism as a food source (Shchepin et al. 2014). However, only twenty of these species have been grown without a live bacterial or yeast food source and of these twenty only ten have been grown on a semi-defined medium containing yeast extract, peptone, glucose and minerals (see Hu \& Clark 1986). These ten species also included the four species which have been grown on a defined minimal medium: Physarum flavicomum (Henney \& Lynch 1969), P. polycephalum (Daniel at al. 1963), P. rigidum (Henney \& Lynch 1969), and Stemonitis flavogenita (Clark et al. 1990). These defined minimal media were relatively simple and similar in all four cases; consisting of minerals, several vitamins, amino acids, glucoses and hematin. The growth of unrelated Stemonitis and Physarum spp. on similar simple minimal media suggests that at least some myxomycete plasmodia have simple basic nutritional requirements. On the other hand, most myxomycetes species have not been cultured even in crude xenic cultures. These conflicting observations are difficult to reconcile, but it may turn out that specific growth parameters such as $\mathrm{pH}$ and the presence or absence of particular compounds, such as hematin, are more important for most myxomycetes than the underlying basic nutritional requirements.

\section{Plasmodial Coalescence}

Since myxomycete plasmodia do not have a cell wall and the phaneroplasmodial and aphanoplasmodia types routinely undergo fusion during formation of the reticulum, the 
maintenance of separate genetic individuals is apparently insured by genetic barriers that prevent coalescence (see review by Clark \& Haskins 2012). This system consists of a three tiered polygenic complex with dominant and recessive alleles (Ling \& Clark 1988) Thus, plasmodia must be phenotypically identical for approximately 16 loci in order to fuse (CC and Cc are phenotypically identical, but different from cc). The first level of the system (having a minimum of seven Fus loci) controls membrane fusion, and it apparently prevents fusion unless the two plasmodia have identical membrane or slime sheath components. The second level (having a minimum of six $\mathrm{Cz}$ loci) produces a rapid lysis of a small mixed region, of the two plasmodia, if membrane fusion has occurred. This lysis is directional in that it targets the recessive phenotype, and it is apparently triggered by some pre-formed substances when they come into contact with a different plasmodium (Clark \& Collins 1972). The third level (having a minimum of three Let loci) comes into play if membrane fusion occurs and there is no rapid lysis of the mixed plasmodium; it produces a slow lethal reaction, which targets and degrades the nuclei of the recessive phenotype (Carlile 1976). This reaction occurs over a period of five to twenty hours and requires the synthesis of new RNA and proteins (Schrauwen 1981). Since, this complex system can produce a minimum of 65,536 different incompatibility phenotypes; it is highly unlikely that any two phaneroplasmodia will undergo a successful fusion unless they are very closely related. Species with aphanoplasmodia apparently have a similar system (Haskins 1990) but species with small protoplasmodia do not appear to undergo any type of plasmodial fusion (Haskins 1978). While this complex incompatibility system usually produces a situation in nature where most of the plasmodia in a region have diverse incompatibility phenotypes (ElHage et al. 2000, Irawan et al. 2000), in at least one case a single phenotype has been shown to occur broadly over several square kilometers and to have persisted for several years (Stephenson et al. 2004).

\section{Senescence}

The plasmodia of most strains of Physarum polycephalum (Poulter 1969) and Didymium iridis (Lott \& Clark 1980) when maintained by routine serial subculture on agar will undergo a senescence phase and die. The lifespan, from syngamy to necrosis is controlled by the genome of the individual plasmodium and is minimally affected by most environmental factors excepting temperature (Clark \& Lott 1981); with a decreasing lifespan with increasing temperatures. Most plasmodia that are isolated from nature display plasmodial senescence (Clark 1984), although some are apparently immortal, and others develop immortality (Hu et al. 1985) or become senescence (Kerr \& Waxlaw 1968) when cultured on agar. However, when Physarum polycephalum is grown in axenic shake culture it does not display an obvious senescence phase (Poulter 1969, Hu et al. 1985); but when transferred to non-axenic agar culture the plasmodium will undergo senescence and die within a short period of time; which is reversely correlated with the length of time that the plasmodium was maintained in axenic shake culture ( $\mathrm{Hu}$ et al. 1985). On the other hand, when transferred to axenic agar culture, the senescence phase does not result in death since the plasmodium recovers and undergoes a new growth phase; followed by a recurrent series of short senescence and growth phases while maintained on agar (Hu et al. 1985). During the senescence phase there is a slow loss of function, with plasmodial fragmentation, pigment loss, accumulation of polyploidy nuclei (McCullough et al. 1973, Clark \& Mulleavy 1982), and degeneration of mitochondria (Hu et al. 1985, Abe et al. 2000). A possible explanation of the axenic shake culture immortality and recurrent senescence on axenic agar is that senescence is due to degeneration of mitochondrial DNA; with fragmentation of the plasmodium and selection for micro-plasmodia having functional mitochondrial DNA allowing continued growth. In shake culture this fragmentation occurs continuously, and on agar culture it occurs during senescence. However, in non-axenic agar culture, the extremely small fragments apparently do not normally survive the rigors of the mixed organism culture. This possibility is supported by age heterokaryon studies, which are made possible by the vegetative amoeboflagellate stage which also serves as gametes (Collins 1963). A single isolated amoeboflagellate will grow and produce a clonal population that can be maintained indefinitely in culture; therefore two clones can be crossed at different times 
(thus being of different ages) to produce isogenic plasmodia that can fuse to form an age heterokaryon (a single plasmodium with nuclei and organelles of different ages). These age heterokaryons, in almost all cases, die concurrently with the oldest plasmodial control (Clark \& Hakim 1980), even when the heterokaryon was formed with a much smaller segment of the older plasmodium (Clark \& Lott 1989). Thus, the older plasmodial portion apparently controls the lifespan of the age heterokaryon, possibly by means of an infectious mitochondrial degeneration. A study (Nakagawa et al. 1993) of the mitochondrial DNA of an immortal strain of Physarum polycephalum, found that it contained several rearrangements associated with a plasmid integration, and that a sub-strain which displayed senescence on agar had a deletion of one of these rearrangements; thus adding support to the mitochondrial theory of aging in the myxomycetes. While mitochondrial degeneration may be the immediate cause of senescence, the evidence for nuclear involvement (McCullough et al. 1973, Clark \& Hakim 1980, Lott \& Clark 1980) is also strong; however, these results need not be in conflict, since nuclear genes could be involved in the control and modulation of the mitochondrial degeneration system.

\section{Sclerotium}

The sclerotium is a resistant structure formed by the plasmodium when it is subjected to adverse environmental conditions. This dormant stage is not required to complete the life cycle, but may be important under certain circumstances, where growth is interrupted due to short or long term unfavorable conditions. This characteristic may be especially valuable to species that inhabit extreme environments such as deserts, snow banks or the bark of trees, where rapid swings in temperature and moisture may occur. Conditions which have been reported to induce the sclerotial state are temperatures below the growth minimum (deBary 1887, Macbride 1922, Jump 1954), slow desiccation (Macbride 1922, Luyet \& Gehenio 1944, Jump 1954), certain heavy (Fe, Cu, Zn) metals (Jump 1954), low pH (Jump 1954), and starvation under conditions that prevent sporulation (Daniels \& Rusch 1961). Scerotia, under laboratory conditions, may retain their viability for several years (Gehenio 1944, Lonert 1965); however, eight to sixteen months is a more general average for most longevity studies (deBary 1887, Gehenio 1944, Jump 1954). The basic structure of the scerotium is the spherule; a round to ovoid cell of variable size (up to 25 microns in diameter) with an amorphous fibrous wall (Aldrich \& Blackwell 1976) and a variable (0 to 14) number of nuclei (Jump 1954). The overall morphology of the sclerotium can be quite variable; however, phaneroplasmodia generally produce a compact mass of spherules with a horny consistency, although a looser more irregular grouping may occur in the same species (Nauss 1943) and aphanoplasmodia generally produce loose strings, clusters or individual groupings of spherules (Alexopoulos 1963, Wollman 1966, Haskins 1974). Each protoplasmodium of Echinostelium minutum forms a single cyst (spherule) with a wrinkled single layered fibrillar wall under adverse conditions (Haskins et al. 1985). Once, favorable growth conditions reoccur, these resistant structures rapidly (in 3 to 24 hours) excyst and return to normal plasmodial activities (Lonert 1965, Haskins et al. 1985).

\section{Sporulation}

The natural end point of the assimilative plasmodial stage of the myxomycetes is sporulation, which is a necessary step in the life cycle. During sporulation the entire plasmodium is converted to one or more sporophores, depending upon the species and type of plasmodium. However, subcultures of the same plasmodium keep under growth conditions do not sporulate; and thus sporulation must be induced by particular environmental factors. Numerous studies have been conducted to determine these factors, and although the results have often been contradictory and difficult to interpret, there is a general consensus that most plasmodia require an aging and or starvation period prior to a light trigger before they can sporulate. However, other conditions which affect the vigor of the plasmodium, such as $\mathrm{pH}$ and temperature extremes (Gray 1938, Collins 1959), can also inhibit sporulation. 


\section{Aging and or starvation}

Klebs (1900) and Camp (1937a) appears to be the first researchers to conclude that starvation was a primary factor in plasmodial sporulation, since they could maintain the plasmodia of a number of species in the vegetative condition for long periods by means of serial sub-culturing. However, Gray (1938) who studied some of the same species, including Physarum polycephalum, concluded that while starvation enhanced and sped up sporulation, it was not necessary, since fed cultures would also sporulate. Ling (1968) also found that progressive starvation produced progressively better sporulation in Didymium iridis. On the other hand, Schure (1949) found that Mucilago crustacean never sporulated when a nutrient organism (baker's yeast) was present in the culture. The sporulation of Physarum polycephalum grown in defined medium was investigated by Daniel \& Rusch (1962), who found that optimal sporulation required a mature plasmodium (just prior to nutrient exhaustion), four days of starvation in the dark on a minimum medium containing only salts and niacin or tryptophane, and a light trigger. They concluded that the niacin was somehow involved with sensitivity to the light trigger, and was probably not a metabolic precursor needed for sporulation. The present authors, who have cultured multiple isolates of many species of myxomycetes, have reached certain conclusions concerning aging and starvation from their long history of culturing myxomycetes. A few species or isolates, usually those from ephemeral habitats, sporulate after a short period of active growth even when abundant nutrients are present; since they are difficult to maintain in culture by serial sub-culture. Apparently, these isolates commit to sporulation after reaching a certain growth age. However, the plasmodia of most species and isolates can be kept in the vegetative stage for long periods by means of serial sub-cultures, and do not sporulate until they are starved. We believe that reports of fed plasmodia of these species undergoing sporulation, is due to culture problems which disrupt the growth and nutrition of the plasmodium. These culture problems could be the accumulation of staling products (continuous feeding in the same culture), $\mathrm{pH}$ changes, and the growth of adverse microorganisms; all of which could produce a pseudo starvation situation.

\section{Light}

It is sometimes suggested that plasmodia become phototrophic just prior to sporulation, and thus migrate to the surface of the substrate where optimal spore dispersal can occur. Whether this is true or now has not been investigated, and since most species sporulate at night (Miller 1898), as anyone who has studied sporulation can attest, it may be correct since the plasmodium usually moves to its sporulation position in the evening prior to sporulation. The requirement of a light trigger to induce sporulation was extensively investigated by Gray (1938). He conclude that plasmodia with colored pigment granules required a light trigger, that plasmodia with white pigment granules may require a light trigger and that unpigmented plasmodia did not require a light trigger; and that those plasmodia that did require a light trigger were stimulated to produce sporangia more quickly with higher light intensities (up to a certain maximum level of intensity). Vouk (1910) had earlier reported that unpigmented plasmodia could sporulate in either light or darkness, and this conclusion has been generally supported by other investigators except for McManus' (1961a) report that Stemonitis fusca required a light stimulus to sporulate. The possibility (Straub 1954, Scholes 1962) that some white pigmented plasmodia (and some colored pigmented) did not required a light trigger was quieted by Ling's (1968) finding that in Didymium iridis the minimum white light trigger could be as low as five seconds at 30 foot-candles of intensity. Investigations on the action spectrum of sporulation (Gray 1939, Straub 1954, Rakoczy 1967) indicated that blue light was the most stimulatory and green light was inhibitory to sporulation; and while some of the yellow plasmodial pigments have a similar absorption spectrum (Lieth 1954), no one, to date, has been able to positively identify them as the photoreceptor pigment. 


\section{Discussion}

Multinucleate amoeboid trophic stages (plasmodia) are relatively common in the Amoebozoa super-group to which the Myxomycetes belong (Adl et al. 2012); however, outside of the myxomycetes, they are most common in the protostelid groups (produce stipitate sporophores) which are scattered throughout the super-group, with plasmodia frequently occurring in the Cavosteliida, Protosporangiida (Ceratiomyxales and Protosporangium), and Schizoplasmodiida (Spiegel et al. 1995). Some of these plasmodia are reticulate and are capable of fragmentation and possibly they may able to fuse (Spiegel personnel communication). Their life cycles may also include an amoeboflagellate stage, and there are indications of a possible sexual cycle in some species (Adl et al. 2012), besides that found in Ceratiomyxa fructiculosa. Thus, the plasmodial state is either an ancestral morphology that has been lost in many taxa, or it is a morphology that has been evolved separately in many different taxa.

The plasmodium is often associated with the production of spores, which generally provides both an efficient means of dispersal and a resistant structure that can withstand temporary adverse conditions. This relationship may be due to the ability of the plasmodium to devote resources to the production of a complex sporophore; that provides access to spore dispersing turbulent air conditions. While some sporophore producing protostelids have uninucleate trophic stages, they are greatly restricted in size and form since the spore requires the great majority of the resources present in the amoeba. Plasmodial protostelids, on the other hand, may produce multinucleate single spores, multispored sporocarps, or a number of individual single spored units (Adl et al. 2012). The only other mechanism for sporophore production available to amoebae is the aggregation and differentiation model of the dictyostelids. Thus, plasmodial size, made possible by the multinucleate state, has apparently allowed the myxomycetes to evolve their large elaborate fruiting structures containing large numbers of spores; which provides the group with an efficient dispersal mechanism not present in most other Amoebozoans. This size advantage may also provide a competitive advantage in terms of habitat and nutritional competition (Haskins 1990). The ability to form a large trophic stage, and to rapidly increase its mass by fusion of genetically identical young plasmodia, can quickly produce a large mobile efficient food gathering structure, that could not only outcompete smaller organisms, but could also ingest many of them. On a final note, Haskins plasmodial film cited in the references can now be viewed on-line by going to AVPortal: TIB, then opening up the portal up and search for $\mathrm{C} 1220$ to view the specific film, or Haskins $\mathrm{E} F$ to view his series of films on myxomycetes.

\section{Acknowledgements}

This review is an attempt to distill the work and ideas of a great many researchers. However, such an attempt can never do justice to everyone's contribution, and we can only say that we tried to do our best, and hope that we have not committed too many major omissions.

\section{References}

Abe T, Takano H, Sasaki N, Mori K, Kawano S. 2000 - In vitro DNA fragmentation of mitochondria DNA caused by single-stranded breakage related to macroplasmodial senescence of the true slime mold Physarum polycephalum. Current Genetics 37, 125-135.

Adl S, Simpson A, Lane C, Lukes J, Bass D, Bowser S, Brown M, Burki F, Dunthorn M, Hampl V, Heiss A, Hoppenrath M, Lara E, Gall L, Lynn D, McManus H, Mitchell E, MuzkyStanridge S, Parfrey L, Pawlowski J, Rueckert S, Shadwick L, Schoch C,

Smirnov A, Spiegel F. 2012 - Classification of Eukaryotes. Journal of Eukaryotic Microbiology 59, 429-493.

Aldrich HC. 1966 - A study of the ultrastructural details of morphogenesis in the myxomycete Physarum flavicomum. Ph.D. Dissertation, University of Texas at Austin. 
Aldrich HC, Blackwell M. 1976 - Resistant structures in the myxomycetes. In (Eds. Weber D, Hess W.) The fungal spore: form and function. John Wiley and Sons, New York.

Aldrich HC, Daniels JW. (Eds.). 1982 - Cell biology of Physarum and Didymium. Volume 1. Organisms, nucleus and cell cycles. Volume 2. Differentiation, metabolism and methodology. Academic Press, New York.

Alexopoulos CJ. 1960 - Gross morphology of the plasmodium and its possible significance in the relationships among the Myxomycetes. Mycologia 52, 1-20.

Alexopoulos CJ. 1963 - The Myxomycetes. II. Botanical Review 29, 1-79.

Alexopoulos CJ. 1964 - The white form of Physarella oblonga. Mycologia 56, 550-554.

Anderson RW. 1977 - A plasmodial colour mutation in the myxomycete Physarum polycephalum. Genetic Research, Cambridge 30, 301-306.

Bailey J, Anderson RW, Dee J. 1990 - Cellular events during sexual development from amoeba to plasmodium in the slime mold Physarum polycephalum. Journal of General Microbiology 136, 739-751.

Daniel J, Babcock K, Sievert A, Rusch H. 1963 - Organic requirements and synthetic media for growth of the myxomycete Physarum polycephalum. Journal of Bacteriology 86, 324-331.

De Bary A. 1887 - Comparative morphology and biology of the fungi, Mycetozoa and bacteria. Clarendon Press, London.

Camp WG. 1937a - The fruiting of Physarum polycephalum in relation to nutrition. American Journal of Botany 24, 300-303.

Camp WG. 1937b - The structure and activities of the myxomycete plasmodia. Bulletin of the Torrey Botanical Club 64, 307-335.

Carlile CJ. 1976 - The genetic basis of the incompatibility reaction following plasmodial fusion between different strains of the myxomycete Physarum polycephalum. Journal of General Microbiology 93, 371-376.

Casser L, Steffan B, Steglich W. 1987 - The chemistry of the plasmodial pigments of the slime mold Fuligo septica (Myxomycetes). Angewandte Chemie 28, 586-587.

Čelakovský L. 1893 - Ueber die Aufnahme lebender und todter verdaulicher Körper in die Plasmodien der Myxomyceten. Flora order Botanische Zeitung 76, 182-244.

Cienkowski L. 1863 - Das Plasmodium. Jahrbüchen fûr Wissenschaftliche Botanik 3, 325-337.

Clark J.1984 - Lifespan and senescence in six slime molds. Mycologia 76, 366-369.

Clark J, Brown D, Hu F-S. 1990 - Growth of the myxomycete Stemonitis flavogenita on a defined minimum medium. Mycologia 82, 385-386.

Clark J, Collins OR. 1972 - Directional cytoplasmic reactions between incompatible plasmodia of Didymium iridis. Genetics 73, 247-257.

Clark J, Hakim R. 1980 - Aging of plasmodial heterokaryons in Didymium iridis. Molecular and General Genetics 178, 419-422.

Clark J, Haskins EF. 2010 - Reproductive systems in the myxomycetes: a review. Mycosphere 1, 337-367.

Clark J, Haskins EF. 2012 - Plasmodial incompatibility in the myxomycetes: a review Mycosphere 3, 143-155.

Clark J, Haskins EF. 2013 - The nuclear reproductive cycle in the myxomycetes: a review. Mycosphere 4, 233-248.

Clark J, Haskins EF, Stephenson SL. 2004 - Culture and reproductive systems of 11 species of Mycetozoa. Mycologia 96, 36-40.

Clark J, Lott T. 1981 - Aging in the acellular slime mold Didymium iridis: Temperature and nutritional effects. Experimental Mycology 5, 369-372.

Clark J, Lott T. 1989 - Age heterokaryon studies in Didymium iridis. Mycologia 81, 636-638.

Clark J, Mulleavy P. 1982 - The effects of polyploidy on life span of Didymium iridis. Experimental Mycology 6, 71-76.

Collin OR. 1959 - Some affects of temperature and pH on the life cycle of Fuligo cinerea (Schw.) Morgan in laboratory culture. Master's Thesis, University of Iowa, Iowa City. 
Collins OR. 1963 - Multiple alleles at the incompatibility locus in the myxomycete Didymium iridis. American Journal of Botany 50, 477-480.

Collins OR, Clark J. 1966 - Inheritance of the brown plasmodial pigment in Didymium iridis. Mycologia 58, 743-751.

Collins OR, Tang HC. 1973 - Physarum polycephalum: $\mathrm{pH}$ and plasmodial formation. Mycologia $65,232-236$.

Constantineanu JC. 1907 - Uber die Entwicklungsbedigungen der Myxomyceten. Annales Mycologici Editi in Notitiam Scientiae Mycologicae Universalis Berlin 4, 495-540.

Czeczuga B. 1980 - Investigations on carotenoids in fungi VII. Representatives of the myxomycetes genera. Nova Hedwigia 32, 347-354.

Daniel JW, Rusch HP. 1961 - The pure culture of Physarum polycephalum on a partial defined soluble medium. Journal of General Microbiology 25, 47-59.

Daniel JW, Rusch HP. 1962 - Niacin requirement for sporulation of Physarum polycephalum. Journal of Bacteriology 83, 1244-1250.

Dugus DJ, Bath JD. 1962 - Electron microscopy of the slime mold Physarum polycephalum. Protoplasma 54, 421-431.

ElHage N, Clark J, Little C, Stephenson SL. 2000 - Biosystematics of the Didymium squamulosum complex. Mycologia 92, 54-64.

Fiore-Donno AM, Nikelaeu SI, Nelson M, Pawlowski J, Cavalier-Smith T, Baldauf SL. 2009 Deep phylogeny and evolution of slime molds (Mycetozoa). Protist 161, 55-70.

Gray WD. 1938 - The effect of light on the fruiting of Myxomycetes. American Journal of Botany 25, 511-522.

Gray WD, Alexopoulos CJ. 1968 - Biology of the Myxomycetes. Ronald Press, New York.

Gehenio PM. 1944 - Longevity of the sclerotia of Mycetozoa. Biodynamica 4, 359-368.

Guttes E, Guttes S, Rusch HP. 1959 - Synchronization of mitosis by the fusion of the plasmodia of Physarum polycephalum. Federation of American Society of Experimental Biology Federation Proceedings 18, 479.

Haskins EF. 1974 - Stemonitis flavogenita (Myxomycetes) - plasmodial phase (aphanoplasmodium). Film E2000 des Institut fûr Wissenschaftlichen Film Göttingen. Publikationen zu Wissenschaftlichen Film, Sektion Biologie 8, 1-14.

Haskins EF. 1978 - The occurrence of binary plasmotomy in the protoplasmodium of the white spored Echinostelium minutum. Mycologia 70, 192-196.

Haskins EF. 1981 - Some observations on sporulation in the myxomycete Stemonitis flavogenita. Journal of the Elisha Mitchell Society 97, 139-144.

Haskins EF. 1990 - Plasmodial coalescence in Stemonitis flavogenita (Myxomycetes, Stemonitales). Mycologia 52, 643-647.

Haskins EF, Kerr NS. 1976 - Vergleich der Plasmodien Typen und der Sporulation bei Myxomyceten. Film C1220 des Institut fûr Wissenschaftlichen Film Göttingen. Publikationen zu Wissenschaftlichen Film, Sektion Biologie 11, 1-34..

Haskins EF, Hinchee AA. 1974 - Light and ultra-microscopic observations on the surface structure of protoplasmodium, aphanoplasmodium, and phaneroplasmodium (Myxomycetes). Canadian Journal of Botany 52, 1835-1839.

Haskins EF, Hinchee AA, McGuinness MD. 1985 - The amoebal and protoplasmodial cyst phases of Echinostelium minutum. Mycologia 79, 253-258.

Haskins EF, Wrigley de Basanta H. 2008 - Methods of agar culture of myxomycetes - an overview. Revista Mexicana de Micologia 27, 1-7.

Hatano S, Oosawa F. 1964 - Actin-like protein of myxomycete plasmodia. IV. Purification and observations of some physio-chemical properties. Annual Report of the Research Group on Biophysics in Japan IV, 35-28.

Henney H, Lynch T. 1969 - Growth of Physarum flavicomum and Physarum ridigum in chemically defined minimal medium. Journal of Bacteriology 99, 531-534. 
Hinchee AA, Haskins EF. 1980 - Closed spindle nuclear divisions in the plasmodial phase of the acellular slime mold Echinostelium minutum. Protoplasma 102, 235-252.

Howard FL. 1931 - Laboratory cultivation of myxomycete plasmodia. American Journal of Botany $18,624-628$.

Howard FL. 1932 - Nuclear division in plasmodia of Physarum. American Journal of Botany 46, 461-477.

Hu F-S, Clark J. 1986 - Axenic culture of the myxomycete Stemonitis flavogenita. Mycologia 78, $478-482$.

Hu F-S, Clark J, Lott T. 1985 - Recurrent senescence in axenic cultures of Physarum polycephalum. Journal of General Microbiology 131, 811-815.

Indira PU, Kalyanasundaram R. 1963 - Some investigations in culture of some myxomycetes. Berichte der Schweizerischen Botanischen Gesellschaft 73, 381-388.

Irawan B, Clark J, Stephenson SL. 2000 - Biosystematics of the Physarum compressum morphospecies. Mycologia 92, 884-893.

Jarocki J. 1931 - Mycetozoa from the Czarnohora Mountains in the Polish eastern Carpatrans. Bulletin de l'Academie Polonaise des Sciences. Série des Sciences Biologique 2, 447-464.

Jump JA. 1954 - Studies on sclerotization in Physarum polycephalum. American Journal of Botany 26, 561-567.

Kamby P. 1930. - The color of myxomycete plasmodia. American Journal of Botany 26, 386-390.

Kamiya N. 1950a - The protoplasmic flow in the myxomycete plasmodium as revealed by a volumetric analysis. Protoplasma 39, 344-357.

Kamiya N. 1950b - The rate of protoplasmic flow in the myxomycete plasmodium I. Cytology 15 , 183-193.

Kamiya N, Takata T. 1967 - Movement of the myxomycete plasmodium. V. The motive force of endoplasm-rich and endoplasm-poor plasmodia. Proceedings of the Japanese Academy 43, 537-540.

Kamiya N, Nakajima H, Abe S. 1957 - Physiology of the motive force of protoplasmic streaming. Protoplasma 45, 94-112.

Kerr NS. 1961 - A study of plasmodial formation by the true slime mold, Didymium nigripes. Experimental Cell Research 23, 603-611.

Kerr NS, Waxlaw J. 1968 - A yellow variant of the eumycetozoan Didymium nigripes which exhibits aging. Journal of Experimental Zoology 168, 351-361.

Kerr SJ. 1976 - A comparative study of mitosis in amoebae and plasmodia of the true slime mold Didymium nigripes. Journal of Protozoology 14, 439-445.

Klebs G. 1900 - Zur physiologie der Fortpflanzen einger Pilze. III. Jahrbûcher fûr Wissenschafliche Botanik 35, 80-133.

Koevenig JL, Jackson RC. 1966 - Plasmodial mitosis and polyploidy in the myxomycete Physarum polycephalum. Mycologia 58, 662-667.

Leith H. 1954 - Die pigmente von Didymium eunigripes und ihre Beziehungen zur Lichtabsorbtien. Berichte der Deutschen Botanischen Gesellschaft 67, 323-325.

Leith H, Meyer GF. 1957 - Über den Bau der Pigmentgrandula bei den Myxomyceten. Naturwissenschaftliche 44, 449.

Ling H. 1968 - Light and fruiting in Didymium iridis. Mycologia 60, 966-970.

Ling H, Clark J. 1981 - Somatic cell incompatibility in Didymium iridis: locus identification and function. American Journal of Botany 68, 1191-1199.

Lister A. 1893 - On the division of nuclei in the Mycetozoa. Journal of the Linnean Society, Botany 29, 520-542.

Loewy AG. 1950 - Protoplasmic streaming under anaerobic conditions in a myxomycete.

Journal of Cellular and Comparative Physiology 40, 127-156.

Lonert AC. 1965 - A high-yield method for inducing sclerotization in Physarum polycephalum. Turtox News 43, 98-102. 
Lott T, Clark J. 1980 - Plasmodial senescence in the acellular slime mold Didymium iridis. Experimental Cell Research 128, 455-457.

Luyet BJ, Gehenio PM. 1944 - The lethal action of desiccation on the sclerotia of Mycetozoa. Biodynamica 5, 339352.

Macbride TH. 1922 - The North American Slime Molds. Macmillan, New York.

McCormick JJ, Blomquist JC, Rusch HP. 1970 - Isolation and characterization of an extracellular polysaccharide from Physarum polycephalum. Journal of Bacteriology 104, 1110-1118.

McCullough C, Cooke D, Foxon J, Sudbery P, Grant W. 1973 - Nuclear DNA content and senescence in Physarum polycephalum. Nature New Biology 245, 263-265.

McManus MA. 1961a - Culture of Stemonitis fusca on glass. American Journal of Botany 48, 682588

McManus MA. 1961b - Laboratory culture of Clastoderma debaryanum. American Journal of Botany 48, 884-888.

McManus MA. 1962 - Some observations on the plasmodia of the Trichiales. Mycologia 54, 7890.

McManus MA. 1964 - Cultivation on agar and study of the plasmodium of Licea biforis and Cribraria violacea. Mycologia 58, 470-483.

Miller CO. 1898 - The aseptic cultivation of Mycetozoa. Quarterly Journal of Microbiological Science 41, 43-71.

Mock DL, Kowalski DT. 1976 - Laboratory cultivation of Licea alexopouli. Mycologia 68, 370376.

Nagai R, Kamiya N. 1966 - Movement of the myxomycete plasmodium. II. Electron microscope studies on fibrillar structures in the plasmodium. Proceedings of the Japanese Academy 42, 934-939.

Nakagawa C, Jones E, Miller DL. 1993 - Mitochondrial DNA rearrangements associated with mF plasmid integration and plasmodial longevity in Physarum polycephalum. Current Genetics 33, 178-187.

Nauss R. 1943 - Observations on the culture of Hemitrichia vesparium with special reference to its black plasmodial color. Bulletin of the Torrey Botanical Club 70, 152-163.

Nauss R. 1947 - My garden of slime molds. Journal of the New York Botanical Garden 48, 101109.

Peterson JE. 1953 - Myxomycetes developed on bark of living trees in moist chamber culture. Master's Thesis, Michigan State University, East Lansing.

Poulter R. 1969 - Senescence in the myxomycete Physarum polycephalum. Ph.D. Dissertation University of Leicester

Rakoczy L. 1967 - Antagonistic action of light in sporulation of the myxomycete Physarum nudum. Acta Societatis Botanicorum Poloniae 36, 153-159.

Rhea RF. 1966 - Electron microscopic observations on the slime mold Physarum polycephalum with specific reference to fibrillar structures. Journal of Ultrastructural Research 15, 349379.

Ross IK.1967 - Growth and development of the myxomycete Perichaena vermicularis. I. Cultivation and vegetative nuclear division.

American Journal of Botany 54, 617620.

Ross IK, Shipley GL. 1973 - Sexual and somatic fusion in the heterothallic slime mould Didymium iridis 2. Effects of actinomycin D, cyclohexamide and lysosome stabilizers. Microbios 7, $165-171$.

Schnittler M, Stephenson SL, Novozholov YK. 2000 - Ultrastructure of Barbeyella minutissima (Myxomycetes). Karstenia 40, 159-166.

Scholes PM. 1961 - Some observations on the cultivation, fruiting and germination of Fuligo septica. Journal of General Microbiology 29, 137-148.

Schrauwen JAM. 1981 - Post-fusion incompatibility in Physarum polycephalum: the involvement of DNA. Archives of Microbiology 129, 257-260. 
Schûnemann E. 1930 - Untersuchungen uber die Sexualitat der Myxomyceten. Planta 9, 645-672.

Schure PSJ. 1949 - Nuclear divisions in the fructifications of some myxomycetes and a method of culture to obtain fructifications. Antonie van Leeuwenhoek Journal of Microbiology and Serology 15, 143-161.

Seifriz W, Zetzmann M. 1935 - A slime mold pigment as indicator of acidity. Protoplasma 23, $175-179$.

Shinnick JM, Pallotta DJ, Jones-Brown YR, Youngman PJ, Holt CE. 1978 - A gene, imz, affecting the $\mathrm{pH}$ sensitivity of zygote formation in Physarum polycephalum. Current Cell Differentiation 7, 21-32.

Shchepin O, Novozhilov Y, Schnittler M. 2014 - Nivicolous myxomycetes in agar culture: some results and open problems. Protistology 8, 53-61.

Shipley GL, Holt CE. 1982 - Cell fusion competence and its induction in Physarum polycephalum and Didymium iridis. Developmental Biology 90, 110-117.

Simon HL, Henney HR. 1970 - Chemical composition of slime from three species of myxomycetes. Federation of European Biochemical Societies Letters 7, 80-82.

Solis BC. 1962 - Studies on the morphology of Physarum nicaraguense Mcbr. M.S. Thesis, University of Iowa, Iowa City.

Spiegel FW, Lee SB, Rusk SA. 1995 - Eumycetozoans and molecular systematics. Canadian Journal of Botany 73(Suppl. 1), 738-746.

Stephenson SL, Clark J, Landolt JC. 2004 - Myxomycetes occurring as single genetic strain in forest soils. Systematics and Geography of Plants 74, 287-289.

Stephenson SL, Landolt JC. 1996 - The vertical distribution of dictyostelids and myxomycetes in the soil/liter microhabitat. Nova Hedwigia 62, 105-117.

Steward PA, Steward BT. 1959 - Protoplasmic movement in the slime mold plasmodium: the diffusion drag force hypothesis. Experimental Cell Research 18, 374-377.

Strasburger E. 1884 - Zur Entwickelungs-geschichte der Sporangien von Trichia fallax. Zeitung 42, 305-326.

Straub WC. 1962 - Das Licht bei der Auslösung der Fruchkörperbildung von Didymium nigripes und die Uberstragung der Lichtwirkung durch Plasma. Naturwissenschaftliche 41, 219220.

Tran H, Stephenson S, Pollock E. 2015 - Evaluation of Physarum polycephalum plasmodial growth and lipid production using rice bran as a carbon source. BMC Biotechnology 15, $67-74$.

Vouk V. 1910 - Untersuchungen ûber die Bewegungen der Plasmodien. I. Die Rhythmik der Protoplasma-strömung. Sitzungsberichte der Kaiserlicher Akademie der Wissenschaften. Matematisch-Naturwissenschaften Classe 119, 853-876.

Watanabe A. 1932 - On the plasmodium of the Myxomycetes (translation). Kagaku 10, 418-421.

Wollman C. 1966 - Cultural studies on selected species of myxomycetes. Ph.D. Dissertation, University of Texas, Austin.

Wollman C, Alexopoulos CJ. 1964 - Spore to spore cultivation in agar culture of three Myxomycetes: Comatricha laxa, Perichaena depressa and Licea biforis. Southwestern Naturalist 9, 160-165.

Wollman C, Alexopoulos CJ. 1967 - The plasmodium of Licea biforis in agar culture. Mycologia $59,423-430$.

Zukal J. 1893 - Uber zwei neue Myxomyeten. Oesterreichische Botanische Zeitschrift 43, 133137. 